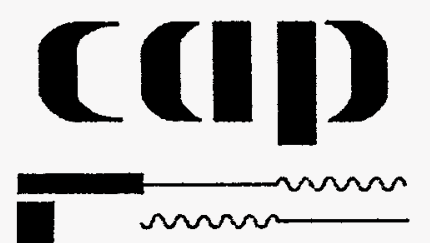

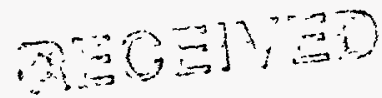

JUL 2 , 3 1597

ㅇ. STI

BNL - 64496

CAP - 182-MUON-97C

CONF-920503--201

A NORMAL CONDUCTING ACCELERATOR FOR A MUON COLIIDER DEMONSTRATION MACHINE*

Y. Zhao, R. Palmer, R. Fernow, J. Gallardo, H. Kirk Department of Physics Brookhaven National Iaboratory

Upton, NY 11973

*This work was performed under the auspices of the 0.5 . Department of Energy under Contract NO. DE-ACO2-76CH00016.

May 1997

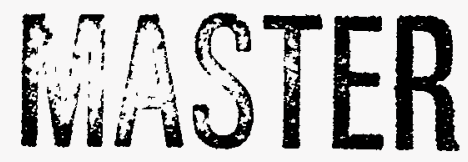

DISTRIBLTIOA OF TIIS DOSUMENT IS UNLMATED

CENTER FOR ACCELERATOR PHYSICS

'

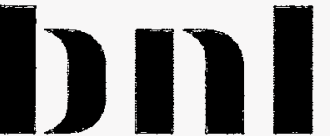

BROOKHAVEN NATIONAL LABORATORY

ASSOCIATED UNIVERSITIES, INC.

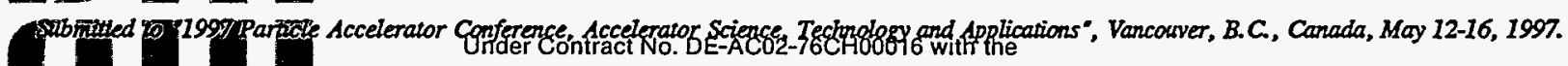

UNITED STATES DEPARTMENT OF ENERGY 


\section{DISCLAIMER}

This report was prepared as an account of work sponsored by an agency of the United States Government. Neither the United States Government nor any agency thereof, nor any of their employees, make any warranty, express or implied, or assumes any legal liability or responsibility for the accuracy, completeness, or usefulness of any information, apparatus, product, or process disclosed, or represents that its use would not infringe privately owned rights. Reference herein to any specific commercial product, process, or service by trade name, trademark, manufacturer, or otherwise does not necessarily constitute or imply its endorsement, recommendation, or favoring by the United States Government or any agency thereof. The views and opinions of authors expressed herein do not necessarily state or reflect those of the United States Government or any agency thereof. 


\section{DISCLAMIER}

Portions of this document may be illegible in electronic image produets. Images are produced from the best available original document. 


\title{
A NORMAL CONDUCTING ACCELERATOR FOR A MUON COLLIDER DEMONSTRATION MACHINE
}

\author{
Y.Zhao, R.Palmer, R.Fernow, J.Gallardo, H.Kirk \\ Brookhaven National Laboratory, Upton, NY 11973
}

\section{Abstract}

We present a $250 \mathrm{GeV}$ linac arrangement using normal conducting cavities that could be used for a muon collider demonstration machine. One scenario consists of six 200 $\mathrm{MHz}$ linacs and rapid cycling pulsed magnets to be installed in a tunnel with six straight sections. The RF parameters of the cavities are given. Another scenario consists of $800 \mathrm{MHz}$. Also addressed is the possibility of using normal conducting cavities with liquid nitrogen cooling, which has several advantages.

\section{INTRODUCTION}

The realizability of the muon collider is interesting from both technological and economical points of view. As a first step, a demonstration machine with lower energy is considered. Since the lifetime of muon is short, rapid acceleration is required and thus the RF equipment must take a significant part of the total cost, especially at the final stage, which plays a major role for the energy gain. Superconducting cavity would be desirable in order to save rf power. However, the machine in question will work at a low duty rate, pulse mode, the peak power extracted by the muon beam is $640 \mathrm{~kW}$ average (see later). Besides, the muon decay deposits energy all along its path, which may cause trouble to the super-conductivity. Therefore an alternative, normal conducting scheme was investigated [1].

\section{BASIC PARAMETERS OF THE DEMONSTRATION MACHINE}

Since the muon collider involves lots of new technology, a demonstration machine with reduced energy and luminosity is considered so as to be more realistic. The energy of $250 \mathrm{GeV}$ with intensity of $4 \times 10^{12}$ muon per bunch is considered. Recently, an even lower energy, which may also be interesting from the point of view of physics, has been proposed. In this paper we concentrate only on the final stage of a $250 \mathrm{GeV}+250 \mathrm{GeV}$ machine. Following is a list of basic parameters related to the RF.
Number of beams

Number of bunches

Muons per bunch

Charge per bunch

Repetition rate $2\left(\mu^{+}\right.$and $\mu^{-}$beams

passing same channel)

2 ( 1 for each beam)

$4 \times 10^{12}$

$0.64 \mathrm{C}$

$2.5 \mathrm{~Hz}$

$\begin{array}{ll}\text { Current per beam } & 1.6 \mu \mathrm{A} \\ \text { Injection energy and } \gamma & 50 \mathrm{GeV} / \gamma=473 \\ \text { Output energy and } \gamma & 250 \mathrm{GeV} / \gamma=2366 \\ \text { Average extracted power } & 320 \mathrm{~kW} \text { per beam } \\ \text { Total extracted power } & 640 \mathrm{~kW}\end{array}$

It is also of very much concern about the radiation energy, which is produced due to the muon decay and dissipated along its path, including RF cavities. The decay equation is:

$$
\frac{d N}{d t}=-\frac{N}{\gamma \tau_{\mu}}
$$

where $\mathrm{N}$ is the number of muons, $\gamma$ is the relativistic factor, and $\tau_{\mu}=2.2 \mu \mathrm{s}$ is the muon lifetime in the rest frame. So the decay (radiation) power, $\mathrm{P}_{\mathrm{o}}$ is:

$$
P_{d}=-\gamma E_{\mu 0} \frac{d N}{d t}=\frac{E_{\mu 0}}{\tau_{\mu}} N=N \cdot 7.70 \times 10^{-6} \mathrm{~W}
$$

where $E_{\mu 0}$ is the rest energy of muon. Note that the decay power depends only on the number of muons, but is independent of the energy $\gamma$. For our basic parameters, the instantaneous radiation is $P_{d}=30.8 \mathrm{MW}$ per bunch. The total energy will be the integral of time.

\section{THE CONCERNS FOR THE RF SYSTEM}

\section{I.I Superconducting or normal conducting}

The advantages of superconducting (sc) are saving RF power and possibly higher gradient, which will shorten the acceleration length. However, the minimum average power is $640 \mathrm{~kW}$, while the peak power is three orders higher, so it must work in pulse mode, which complicates the sc system. Besides, the stability in the heavy radiation environment and the capability of handling its heat load are questionable. According to the above data, assuming the accelerating cycling time is $400^{\circ} \mu \mathrm{S}$, then the total radiation power is $61.6 \mathrm{~kW}$ on average. Assuming one third is converted to electrons (or positrons for $\mu^{*}$, the remaining to neutrinos), and that one third of electrons are dissipated at cavity walls, we find the deposit power is 6.8 $\mathrm{kW}$. This is a big load for a sc cryogenic system. The normal conducting (nc) system, on the other hand, requires a much higher if power, which implies a large amount of capital investment. As an improvement, liquid nitrogen cooling has been investigated. The result is encouraging, and will be discussed later. 


\subsection{Frequency}

The higher frequency can run with higher gradient, less stored energy, more compact and less costly. However, the bunch length and transverse emittance will limit the maximum frequency. The availability of power sources is also an important consideration for the frequency choice. In our case, 200 and $800 \mathrm{MHz}$ have been considered. To our knowledge, the largest power available for $200 \mathrm{MHz}$ is with tetrode or triodes only. Triode RCA/Burle 7835 with a maximum long pulse power of $5 \mathrm{MW}$, and tetrode $4 \mathrm{CM} 25000 \mathrm{KG}$ of CPI with a potential power output $7 \mathrm{MW}$ may be the best candidates. For $800 \mathrm{MHz}$, the klystron Litton L-5859 with peak power of $12 \mathrm{MW}$ would be satisfactory.

\subsection{Accelerating Gradient}

The gradient must satisfy two criteria. One is related to the muon lifetime, i.e. after acceleration the number of decayed muons must not be significant. This leads us to the expression:

$$
\bar{E}_{a c c} \gg \frac{E_{\mu 0}}{e c \tau_{\mu}}=0.16 \mathrm{MV} / \mathrm{m},
$$

where $\bar{E}_{a c c}$ is the average gradient throughout the entire muon system [2].

Another criterion is related to the energy drop due to the beam loading, i.e. that energy extracted by the bunch must be much less than the energy stored inside the cavity. It results in the expression:

$$
E_{a c c} \gg q \cdot \frac{4 \pi}{c}(R / Q) f^{2} T^{2} \cos ^{2} \phi,
$$

where $E_{a c c}$ is the accelerating gradient, $\mathrm{q}$ is the charge of the bunch, $R / Q$ the cavity parameter, $f$ the if frequency, $T$ the transit time factor of the cavity, and $\phi$ the synchrotron phase. Since the total charge $q$ is rather large, this data is of concern. The energy drop will be addressed later. These criteria suggest applying the highest gradient possible. However, the maximum gradient is primarily limited by the breakdown. The maximum surface electric field on the cavity wall is considered to be no more than 2 times the Kilpatrick criterion'. Then one would like to reduce the ratio of maximum surface field to the acceleration gradient (or the gap voltage). A noseless cavity has a lower ratio than a cavity with noses (termed reentrant cavity), and it also has a lower $\mathrm{H}_{\mathrm{mu}}$, which determines the maximum surface current density. But, noseless cavities have lower $\mathrm{R} / \mathrm{Q}$ and thus require higher if power. Therefore, if highest gradient is desirable, one tends to use noseless cavities, as in many super-conducting if systems, where the power loss is ignorable. If a normal conducting cavity is used and lower if power is required, then a reentrant cavity is

\footnotetext{
' A multiple of 2.5 or 3 may be possible, but not certain.
}

usually better. A compromise is necessary. Table 1 shows a comparison.

\subsection{The $R F$ power requirement}

Many factors affect the power requirements. The power source must be able to compensate the cavity resistive loss, the energy extracted by the beam, and the energy converted to high order modes (HOM). The finite filling time will require longer pulse length than the real acceleration time. This portion of the energy is reflected from the cavity or dissipated as a pulse tail. The beamextracted power is $640 \mathrm{~kW}$ as mentioned above. HOM losses are generally small, and can be ignored, provided proper depression has been made. The resistive loss is the major part for a normal conducting system. The following equation shows the relation to other parameters.

$$
P=\frac{\lambda}{2} \frac{E_{a c c}}{T^{2} \cos ^{2} \phi} \frac{G}{n} \frac{1}{Q(R / Q)},
$$

where $G$ is the total energy gain of the muons, equal to 200 GV in our case, $\mathrm{n}$ the number of cycling turns, and $\lambda$ the free space wave length. Therefore, increasing $Q$, number of turns, or frequency will reduce the power requirement, while increasing gradient will increase it. The high $R / Q$ of the cavity is desirable from the above equation. The reentrant cavity usually has higher $R / Q$, but also has a higher ratio of maximum surface field to the gap voltage.

\subsection{Voltage drop and energy drop}

In our case the beam loading is very heavy, and the voltage drop can be significant. The voltage induced by the bunch is:

$$
V_{b}=2 T k q=\frac{1}{2} T \omega q(R / Q)
$$

where $k$ is the loss parameter[3],

$$
k=\frac{1}{4 \alpha}=\frac{V^{2}}{4 W}
$$

$\alpha$ is a cavity shape parameter. The relative energy drop has the exact form as follows:

$$
\frac{\Delta W}{W_{c}}=T \frac{\omega(R / Q)}{V_{c}} q \cos \phi,
$$

while the relative voltage drop is roughly a half.

$$
\frac{\Delta V}{V_{c}} \approx \frac{1}{2} \frac{\Delta W}{W_{c}}
$$

The energy stored in the cavity must be much larger than that extracted by the beam in order to avoid instability. The expression (4) is deduced from (8). Moreover, in our scheme both $\mu^{+}$and $\mu^{-}$will pass through the same cavities, while the phase difference between the two bunches varies with the location of cavities. The

\footnotetext{
${ }^{2}$ The formula is in accordance with the definition $R / Q=V^{2} / \omega W$, which has a factor of 2 difference with another frequently used definition of $R / Q$.
} 
voltage induced by two beams differs from cavity to cavity. This factor strengthens the above concern. A lower $R / Q$ is beneficial from above equation.

\section{THE 200 MHZ SCENARIO}

As a paper study example, we considered using the existing RHIC tunnel at Brookhaven National Lab to house the muon accelerator ring. This ring includes 6 straight sections with length of $283 \mathrm{~m}$ for each and a circumference of $3834 \mathrm{~m}$. There would be adequate room for a $250 \mathrm{GeV}$ rapid cycling accelerator. The following parameters were chosen:

$\begin{array}{ll}\text { Number of cycling turns } & 40 \\ \text { Energy gain per turn } & 5 \mathrm{GeV} \\ \text { Linac length } & 6 \times 200 \mathrm{~m} \\ \text { Accelerating gradient } & 4.17 \mathrm{MeV} / \mathrm{m} \\ \text { Revolution time } & 12.77 \mu \mathrm{S} \\ \text { RF effective pulse length } & 510 \mu \mathrm{S}\end{array}$

Cavities were simulated by SUPERFISH. Many options were calculated but not optimized yet. Some results are summarized in Table 1.

Table 1
\begin{tabular}{|l|l|l|l|l|}
\hline Cavity code \# & $200 \mathrm{~A} 3$ & $200 \mathrm{~B} 5$ & $200 \mathrm{~B} 8$ \\
\hline Shape (w/wo nose) & $\mathrm{w}$ & wo & wo \\
\hline Diameter & $\mathrm{cm}$ & 96 & 132 & 128 \\
\hline Iris (diameter) & $\mathrm{cm}$ & 15 & 46 & 30 \\
\hline $\mathrm{E}_{\text {man }}$ & $\mathrm{MV} / \mathrm{m}$ & 34.8 & 11.3 & 10.6 \\
\hline $\mathrm{E}_{\text {man }} / \mathrm{E}_{\text {wlic }}$ & & 2.38 & 0.77 & 0.72 \\
\hline $\mathrm{H}_{\text {man }}$ & $\mathrm{kA} / \mathrm{m}$ & 25.5 & 17.3 & 15.4 \\
\hline Total rf power & $\mathrm{GW}$ & 1.96 & 3.43 & 2.79 \\
\hline Average power & $\mathrm{MW}$ & 2.94 & 5.15 & 4.18 \\
\hline Efficiency & $\%$ & 25.6 & 14.6 & 18.0 \\
\hline Energy drop & $\%$ & 5.59 & 1.93 & 2.55 \\
\hline
\end{tabular}

The reentrant cavity needs less power, but the maximum field is higher. The noseless cavity has more potential to increase gradient, but the power will also increase correspondingly. The energy drop is for one bunch only. For two bunches it will be higher. The worst case is that two bunches, $\mu^{+}$and $\mu^{-}$, enter the same cavity at the same time, then the drop will be doubled.

\section{THE 800 MHZ SCENARIO}

From Equation (5), it is clear that highest frequency is preferable. If it's not restricted to an existing tunnel then a smaller ring with more cycling turns will reduce the power further. We now consider the following parameters:
Frequency

Circumference

Cycling turns $800 \mathrm{MHz}$ $2000 \mathrm{~m}$ 60

Revolution time

$\mathrm{RF}$ effective pulse length $6.67 \mu \mathrm{S}$

\footnotetext{
${ }^{3}$ With pulse length of $600 \mu \mathrm{S}$ as taking the rise time into account.
}

A cavity is simulated via SUPERFISH and Table 2 summarizes some data with different gradients.

Table 2

\begin{tabular}{|l|l|l|l|l|}
\hline Gradient & $\mathrm{MV} / \mathrm{m}$ & 15 & 10 & 5 \\
\hline $\mathrm{E}_{\text {sma }} / \mathrm{E}_{\text {blaca. }}$ & & 1.57 & 1.04 & 0.52 \\
\hline Linac length & $\mathrm{m}$ & 222 & 333 & 667 \\
\hline Cavity loss & $\mathrm{GW}$ & 3.57 & 2.38 & 1.19 \\
\hline Beam load & $\mathrm{GW}$ & 0.64 & 0.64 & 0.64 \\
\hline Total rf power & $\mathrm{GW}$ & 4.21 & 3.02 & 1.83 \\
\hline Average power & $\mathrm{MW}$ & 4.44 & 3.18 & 1.93 \\
\hline Efficiency & $\%$ & 15.2 & 21.2 & 35.0 \\
\hline Energy drop & $\%$ & 8.2 & 12.3 & 24.6 \\
\hline
\end{tabular}

It shows the power requirement is reduced, even though the gradient is higher and with much shorter linac length, implying a significant cut of cost. However, the energy drop is rather large. A further careful treatment is necessary.

\section{LIQUID NITROGEN COOLING}

It is well known that the resistivity of metals decreases with decreasing temperature. Although the cryogenic system is usually expensive, liquid nitrogen is not. At NY it costs 5 cents a liter, cheaper than bottle water. The cooling cost is $\$ 1.13$ per $\mathrm{kWhr}$. At liquid nitrogen temperature, $77 \mathrm{~K}$, the conductivity of copper is 7.5 times better than that at room temperature. For beryllium it is 23 times better than that of copper at room temperature. Assuming this condition is applied, then the $Q$ of the cavity will increase 2.7 and 4.8 times respectively. Taking account that the inner surface temperature of the cavity is higher than the coolant, with a beryllium coating applied, the $Q$ can still be 2.7 times higher. The preliminary study shows it will save a lot of if power and the capital investment.

The challenge is to develop this technology. The concerns are: (1) Does the heat conductivity enable the cavity to reach an adequate low temperature? (2) Does the anomalous skin effect invalidate the estimate? (3) Does the magnetic field surrounding the cavity matter? (4) Is the cost saving for liquid nitrogen really worthwhile? Early studies of the above problems are encouraging.

\section{REFERENCES}

[1] Y.X. Zhao, 'The if consideration of $200 \mathrm{MHz}$ normal conducting accelerator for muon collider demonstration machine', Muon-collider cooperation workshop, Oxiford, Mississippi, Jan 17-18, 1997.

[2] 'Muon Muon Collider, A feasibility Study', BNL52503, Fermi Lab-Conf-96/092, LBNL-38946, July 1996, p.278.

[3] P.B. Wilson: 'High energy electron linacs: Applications to storage ring $\mathrm{RF}$ system and linear collider', SLAC-PUB-2884 (Rev) 1991.

\footnotetext{
${ }^{4}$ With pulse length of $422 \mu S$.
} 